\title{
Interactions of IgG1 CH2 and CH3 domains with FcRn
}

\author{
Tianlei Ying ${ }^{1}{ }^{*}$, Tina W. Ju ${ }^{1}$, Yanping Wang ${ }^{1,2}$, Ponraj Prabakaran ${ }^{1,2}$ and Dimiter S. Dimitrov ${ }^{1}$ \\ 1 Protein Interactions Group, Cancer and Inflammation Program, National Cancer Institute, National Institutes of Health, Frederick, MD, USA \\ ${ }^{2}$ Basic Science Program, Leidos Biomedical Research, Inc., Frederick National Laboratory for Cancer Research, Frederick, MD, USA
}

\section{Edited by:}

Jan Terje Andersen, Oslo University Hospital, Norway

\section{Reviewed by:}

Julia Ponomarenko, University of

California San Diego, USA

Daniel Olive, INSERM UMR 891

Institut Paoli Calmettes, France

${ }^{*}$ Correspondence:

Tianlei Ying, Protein Interactions Group, Cancer and Inflammation

Program, National Cancer Institute, National Institutes of Health, Building 567, Room 185, Frederick, MD 21702, USA

e-mail: yingt@mail.nih.gov
Antibody fragments are emerging as promising biopharmaceuticals because of their relatively small-size and other unique properties. However, when compared to full-size antibodies, most of the current antibody fragments of $\mathrm{VH}$ or $\mathrm{VL}$ display greatly reduced half-lives. A promising approach to overcome this problem is through the development of novel antibody fragments based on IgG Fc region, which contributes to the long half-life of IgG through its unique $\mathrm{pH}$-dependent association with the neonatal $\mathrm{Fc}_{\mathrm{c}}$ receptor (FcRn). The IgG Fc region comprises two $\mathrm{CH} 2$ and two $\mathrm{CH} 3$ domains. In this report, we present a comparative study of the FcRn binding capability of the $\mathrm{CH} 2$ and $\mathrm{CH} 3$ domains. The stability and aggregation resistance of these domains were also investigated and compared. We found that monomeric $\mathrm{CH} 2$ and $\mathrm{CH} 3$ domains exhibited the $\mathrm{pH}$-dependent $\mathrm{FcRn}$ binding while the dimeric forms of $\mathrm{CH} 2$ and $\mathrm{CH} 3$ domains did not. Although all of these domains had high serum stability, they had aggregation tendencies as measured by dynamic light scattering. By providing a better understanding of the structure-activity relationship of the Fc fragment, these results guide further approaches to generate novel Fc-based small-size antibody fragments that possess $\mathrm{pH}$-dependent FcRn binding capability, desired in vivo half-lives, and other favorable biophysical properties for their druggability.

Keywords: FcRn, antibody fragments, $\mathrm{CH} 2$ domain, $\mathrm{CH} 3$ domain, small-size

\section{INTRODUCTION}

Therapeutic antibodies are the fastest growing class of protein biopharmaceuticals, accounting for over half of therapeutic protein sales in 2010. Monoclonal antibodies (mAbs), in particular, are enjoying significant success in the clinic and have been used for the effective treatment of a number of diseases such as cancer and immune disorders (1). Currently, the vast majority of Food and Drug Administration (FDA)-approved therapeutic antibodies and those in clinical trials are full-size antibodies in IgG1 format (2). Due to their large size $(\sim 150 \mathrm{kDa})$, they exhibit poor penetration in tissues and limited binding to surface targets that could be accessible by molecules of smaller size. Therefore, antibody fragments - with a reduced size of $12-50 \mathrm{kDa}$ - have the potential to overcome the fundamental limitations of full-size antibodies. Due to their smaller size, they could achieve enhanced tissue penetration and a wider range of possible targets, as well as require lower production costs $(3-5)$. However, compared to IgG format antibodies, they display greatly reduced half-lives and as such have limited clinical potential.

IgG1 antibodies exhibit extremely long half-lives (up to 3 weeks in circulation) and broad biodistribution due to their unique $\mathrm{pH}$ dependent association with the neonatal $F c$ receptor $(F c R n)$. The FcRn is an intracellular receptor localized in the acidic compartments of endosomes (6). By fluid-phase endocytosis, circulating IgGs enter endosomes, the first step of the proteolytic degradation pathway. However, at the low $\mathrm{pH}$ of the endosome ( $\mathrm{pH} 6.0$ ), IgGs form a complex with FcRn and are then recycled to the cell surface. The higher physiological $\mathrm{pH}$ of the circulation ( $\mathrm{pH}$ 7.4) triggers the release of IgGs from their complex with FcRn back into circulation (7). Therefore, a promising approach to improve half-life is the development of antibody fragments based on the IgG Fc region, which comprises the unit necessary for binding to FcRn. Fc-based fragments can be used to create Fc-fusion proteins and novel antibody scaffolds.

Fc-based fragments have proven to be successful in enhancing the half-life of many drug candidates that alone would have been in circulation for a scale of minutes to hours rather than weeks. These $\mathrm{Fc}$ fusions are composed of the effector domain of a macromolecule linked to the IgG Fc region, which confers a prolonged half-life and better production due to its interactions with FcRn and its relative stability, respectively (8). The first Fc-fusion etanercept $\left(\right.$ Enbrel $\left.^{\mathrm{TM}}\right)$ was introduced in 1998 for the treatment of rheumatoid arthritis (9) and later a broad range of autoimmune diseases. As a tumor necrosis factor (TNF) inhibitor, Enbrel ${ }^{\mathrm{TM}}$ is composed of the TNF receptor fused to the Fc region of IgG1. Since its introduction, this class of therapeutic has grown rapidly, as the FDA has approved several Fc fusions for clinical use.

Fc-derived antibody fragments can also serve as novel antibody scaffolds that exhibit both effector functions and binding to FcRn (10-14). Moreover, the loop regions at the C-terminal of its $\mathrm{CH} 3$ regions can be engineered to form new antigen-binding sites (15). The Fc antigen-binding (Fcab) small-size antibody format developed by F-star has been shown to possess not only properties similar to that of full-size antibodies but also the added benefit of lower production costs. However, to further reduce the size of possible scaffolds, the IgG Fc region can be divided into two $\mathrm{CH} 2$ regions and two $\mathrm{CH} 3$ domains. These domains have the potential to be engineered into even smaller antibody fragments. 
We have previously engineered monomeric $\mathrm{CH} 2$ (16), $\mathrm{CH} 3$ (11), and Fc-based fragments (12). Here, we present a comparative study of the FcRn binding capability of the monomeric and dimeric $\mathrm{CH} 2$ and $\mathrm{CH} 3$ domains. Both monomeric and dimeric $\mathrm{CH} 2$ and $\mathrm{CH} 3$ domains had high serum stability but also aggregation tendencies at different levels. Among these, we found that monomeric $\mathrm{CH} 2$ and $\mathrm{CH} 3$ domains exhibited the $\mathrm{pH}$ dependent FcRn binding. Further, structural modeling studies of these domains in complex with FcRn were performed to understand the molecular basis of the FcRn binding. There results could be helpful to generate novel Fc region-based small-size antibody fragments that possess $\mathrm{pH}$-dependent FcRn binding capability, desired in vivo half-lives, and other biophysical properties.

\section{MATERIALS AND METHODS \\ ANTIBODY EXPRESSION AND PURIFICATION}

All antibody fragments, including $\mathrm{Fc}, \mathrm{mFc}, \mathrm{dCH} 2, \mathrm{CH} 2, \mathrm{dCH} 3$, $\mathrm{mCH} 3$, were expressed in E. coli HB2151, as described previously $(11,12,17)$. The bacterial pellet was collected after centrifugation at $6,000 \times g$ for $15 \mathrm{~min}$, and resuspended in PBS ( $\mathrm{pH} \mathrm{7.4)} \mathrm{con-}$ taining $0.5 \mathrm{M} \mathrm{NaCl}$ and 0.5 milliunits/mL polymyxin B (SigmaAldrich). After $30 \mathrm{~min}$ incubation at room temperature, the bacterial pellet was subsequently clarified by centrifugation at $25,000 \times g$ for $30 \mathrm{~min}$ at $4^{\circ} \mathrm{C}$. The clarified supernatant was used for purification of antibody fragments by using HisTrap HP column (GE Healthcare) according to manufacturer's protocols. Protein purity was determined by SDS-PAGE, and protein concentration was measured spectrophotometrically (NanoVue, GE Healthcare).

\section{DYNAMIC LIGHT SCATTERING}

For comparison of aggregation tendency, the antibody fragments were filtered through a $0.22-\mu \mathrm{m}$ filter (Millipore, Bedford, MA, USA) and adjusted to the same concentration $(0.25 \mathrm{mg} / \mathrm{mL})$. Measurements were performed using a Zetasizer Nano ZS ZEN3600 (Malvern Instruments Limited, Westborough, MA, USA) to determine the size of protein particles. The samples $(0.5 \mathrm{~mL})$ were analyzed in polystyrene cuvettes with a path length of $10 \mathrm{~mm}$ at $25^{\circ} \mathrm{C}$. Each sample was recorded three times with seven subruns of $10 \mathrm{~s}$. The same samples were also used to run size exclusion chromatography (SEC) using FPLC AKTA BASIC pH/C system (GE Healthcare) with a Superdex 75 10/300 GL column. PBS (pH 7.4) was used as running buffer (flow rate $0.5 \mathrm{~mL} / \mathrm{min}$ ), and eluting proteins were monitored at $280 \mathrm{~nm}$. The molecular mass standards used were ribonuclease A $(13.7 \mathrm{kDa})$, chymotrypsinogen $\mathrm{A}$ $(25 \mathrm{kDa})$, ovalbumin $(44 \mathrm{kDa})$, bovine serum albumin $(67 \mathrm{kDa})$, and aldolase $(158 \mathrm{kDa})$, as described previously.

\section{SERUM STABILITY}

The stabilities of $\mathrm{dCH} 2, \mathrm{CH} 2, \mathrm{dCH} 3$, and $\mathrm{mCH} 3$ in serum were evaluated for up to 12 days. Normal human serum was collected from healthy human donors approved by the NCI-Frederick Research Donor Program. Aliquots $(0.1 \mathrm{~mL})$ of each antibody fragment solution $(12 \mu \mathrm{M})$ were mixed with $0.5 \mathrm{~mL}$ of normal human serum to give a final concentration of $2 \mu \mathrm{M}$. The mixture was passed through a $0.22-\mu \mathrm{m}$ filter (Millipore, Bedford, MA, USA), and then incubated at $37^{\circ} \mathrm{C}$. An aliquot was taken out at each time point and immediately stored at $-80^{\circ} \mathrm{C}$. After 10 days incubation, Western blots were performed to check the serum stability.
Samples were electrophoresed through SDS-PAGE and transferred onto $0.2 \mu \mathrm{m}$ nitrocellulose membranes (Bio-Rad). After transfer, membranes were blocked with 3\% milk in PBS for $1 \mathrm{~h}$ and then incubated with anti-His Tag monoclonal antibody (ABM, Vancouver, BC, Canada). Membranes were washed and then incubated with anti-mouse IgG-alkaline phosphatase antibody (Sigma-Aldrich). After washing, immune complexes were detected by reaction with BCIP/NBT substrate solution (Sigma-Aldrich).

\section{FcRn BINDING MEASURED BY ELISA}

Recombinant human single-chain soluble FcRn ( $\mathrm{sFcRn}$ ), containing both $\beta$ and $\alpha$ chains in a 1:1 molar ratio, was expressed in mammalian cells and purified as described previously (18). ELISA wells were coated with sFcRn at $50 \mathrm{ng}$ per well in PBS ( $\mathrm{pH} 7.4$ ) overnight at $4^{\circ} \mathrm{C}$, and blocked with protein-free blocking buffer (Thermo Scientific) at $37^{\circ} \mathrm{C}$ for $2 \mathrm{~h}$. Twofold serially diluted protein, prepared with PBS containing $0.2 \%$ BSA, pH 6.0 or PBS containing $0.2 \% \mathrm{BSA}, \mathrm{pH} 7.4$, was added and incubated at $37^{\circ} \mathrm{C}$ for $1.5 \mathrm{~h}$. The plates were washed with PBST (PBS plus $0.05 \%$ Tween-20), pH 6.0 or $\mathrm{pH} 7.4$, and horseradish peroxidase (HRP)conjugated anti-FLAG tag antibody (Sigma-Aldrich) in PBS (pH 6.0 or 7.4) was incubated with wells for $45 \mathrm{~min}$ at $37^{\circ} \mathrm{C}$. After extensive washes with PBST ( $\mathrm{pH} 6.0$ or 7.4 ), the binding was detected by the addition of ABTS substrate (Roche, Indianapolis, IN, USA), and monitored at $405 \mathrm{~nm}$.

\section{HOMOLOGY-MODELING AND ENERGY MINIMIZATION}

The three dimensional (3D) models of human FcRn, $\mathrm{mFc}, \mathrm{mCH} 2$, and $\mathrm{mCH} 3$ were predicted by using the structural components from the crystal structure of rat FcRn-Fc complex (19) (PBD entry: 1I1A) as templates. Homology-modeling was carried out using SWISS-MODEL workspace (20), a fully automated protein structure homology-modeling server accessible via the ExPASy web server. After the generation of initial coordinates, each of the resulting models was refined by energy minimization using "Not just A Molecular Dynamics" (NAMD) program (21). The structures were solvated in a spherical box of water molecules using VMD program, with a minimal distance of $3 \AA$ from the protein to the box boundary of sphere, and all the histidine residues were assigned as protonated. Systems were first minimized 5,000 steps, followed by a molecular dynamics simulation with the temperature gradually dropped from 350 to $100 \mathrm{~K}$. The system was then re-minimized for 50,000 steps with conjugate gradient method. The non-bonded interaction cutoff distance was set to be $9 \AA$. The final minimized structures were taken for molecular docking.

\section{MOLECULAR DOCKING AND INTERFACE ANALYSIS}

Docking of FcRn and Fc-based fragments were performed using the ZDOCK module (22) on Discovery Studio 2.5 (Accelrys Inc.), which uses a grid-based representation of two proteins and a $3 \mathrm{D}$ fast Fourier transform (FFT) to effectively explore the rigid body search space of docking positions. The top ranked complex prediction, formed by the receptor $\mathrm{FcRn}$ and the ligand $\mathrm{mFc}, \mathrm{CH} 2$, or $\mathrm{mCH} 3$, were solvated and subjected to further dynamic simulations run for $250 \mathrm{ps}$, with other parameters the same as above, to allow adjustment of the positions of side-chains and helices. The final minimized complex structures were analyzed by using 


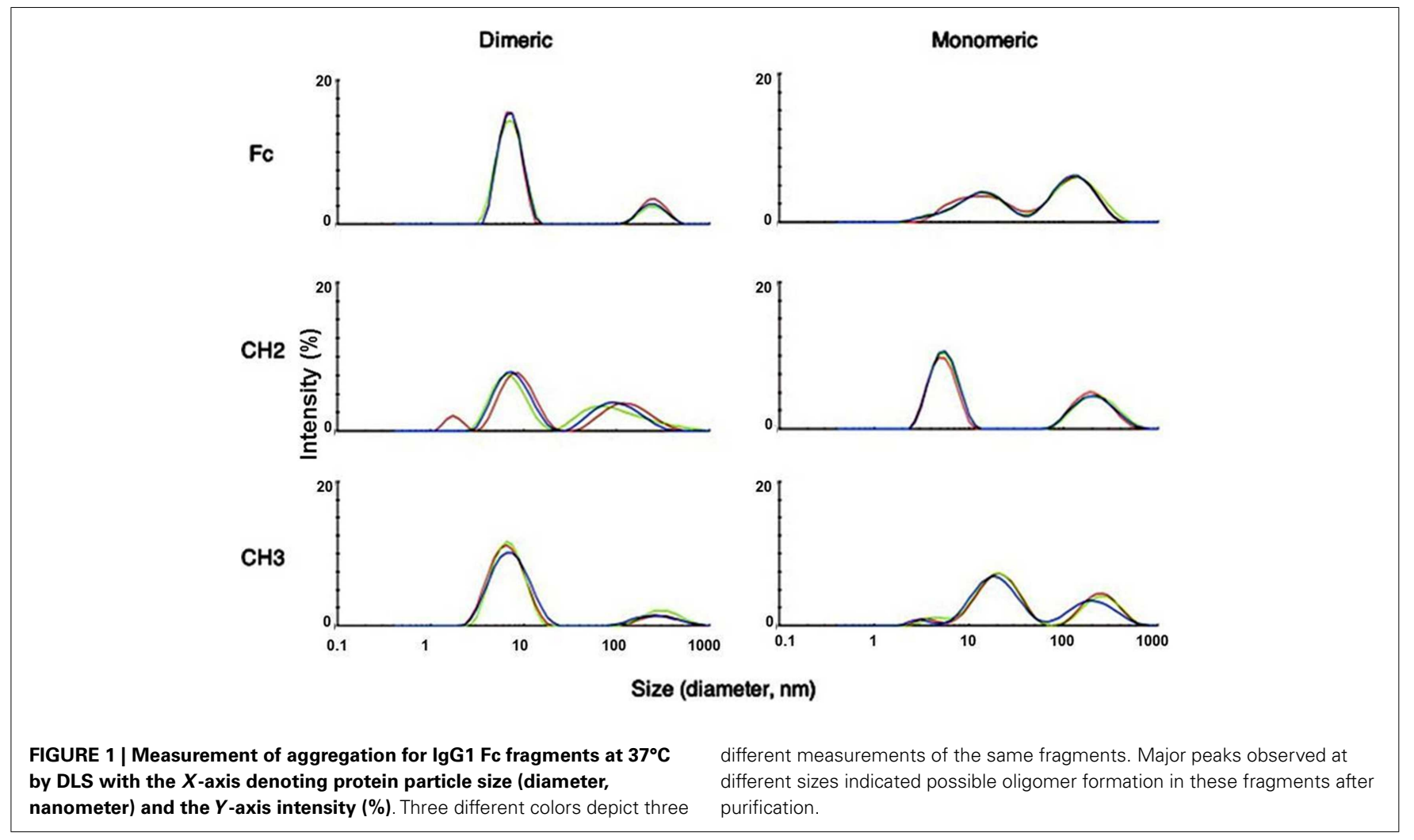

VMD software (23) and PDBePISA (24), an interactive tool for the exploration of macromolecular interfaces at the European Bioinformatics Institute.

\section{RESULTS AND DISCUSSION}

AGGREGATION PROPENSITIES OF Fc, mFc, dCH2, CH2, dCH3, AND mCH3 FRAGMENTS

We used dynamic light scattering (DLS) to measure the aggregation tendencies of Fc-based fragments consisting of $\mathrm{Fc}, \mathrm{CH} 2$, and $\mathrm{CH} 3$ in monomeric and dimeric forms at $37^{\circ} \mathrm{C}$. We observed that both dimeric $\mathrm{Fc}$ and $\mathrm{dCH} 3$ had a major peak at a smaller size followed by a minor peak at a larger size indicating the predominance of monomeric species with the lesser extent of soluble oligomers (Figure 1). In contrast, the peaks at the larger size were increased for $\mathrm{mFc}, \mathrm{mCH} 3, \mathrm{dCH} 2$, and $\mathrm{CH} 2$ reflecting the formation of large soluble oligomers of these fragments. Interestingly, the supernatants from most of the fragments were still monomeric according to the results obtained by using SEC (data not shown). Such findings indicate that the formation of the soluble oligomers may be reversible and the oligomers disassociate to monomers in diluted condition when running SEC.

\section{SERUM STABILITY OF dCH2, mCH2, dCH3, AND CH3 FRAGMENTS}

We evaluated the stability of $\mathrm{dCH} 2, \mathrm{mCH} 2, \mathrm{dCH} 3$, and $\mathrm{CH} 3$ fragments in serum. Samples were incubated with human serum at $37^{\circ} \mathrm{C}$, and an aliquot was taken out at each time point, for every other day, and stored at $-80^{\circ} \mathrm{C}$ before Western blot (Figure 2) analyses for up to 12 days. These data suggest that dimeric and different measurements of the same fragments. Major peaks observed at essible oligomer formation in these fragments after

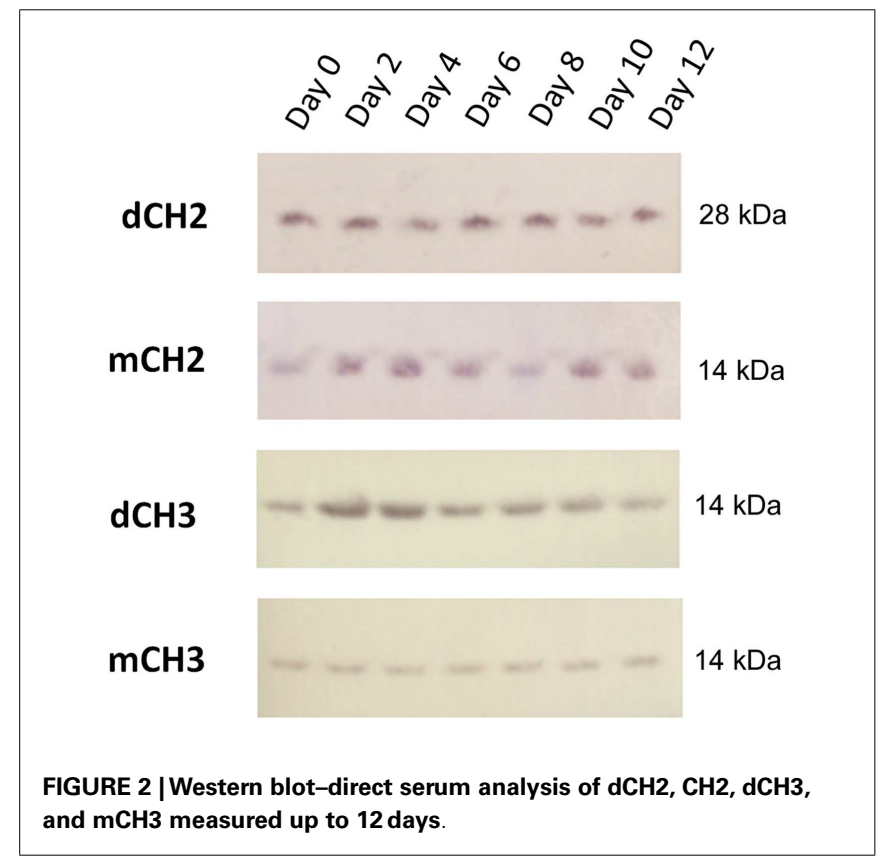

monomeric fragments of $\mathrm{CH} 2$ and $\mathrm{CH} 3$ domains have high serum stability.

\section{MONOMERIC CH2 AND CH3 FRAGMENTS BIND TO FcRn}

To test whether the $\mathrm{dCH} 2, \mathrm{mCH} 2, \mathrm{dCH} 3$, and $\mathrm{mCH} 3$ fragments are functional and behave in a manner similar to wild-type or $\mathrm{mFc}$, 
ELISA binding experiments were carried out to validate their $\mathrm{pH}$ dependent binding to FcRn. The binding was performed under $\mathrm{pH} 6.0$ and $\mathrm{pH}$ 7.4, respectively, as described in the experimental method section. As shown in Figure 3, the $\mathrm{mCH} 2$ and $\mathrm{mCH} 3$ fragments displayed a behavior similar to that of the wild-type or $\mathrm{mFc}$. At $\mathrm{pH}$ 6.0, the $\mathrm{mCH} 2$ and $\mathrm{mCH} 3$ fragments showed detectable binding to FcRn (Figure 3A) while dCH2 and dCH3 did not show any binding to FcRn. At $\mathrm{pH} 7.4$, neither wild-type Fc nor the fragments showed detectable binding to FcRn (Figure 3B). These results suggested that the $\mathrm{mCH} 2$ and $\mathrm{mCH} 3$ maintained characteristic $\mathrm{pH}$-dependent $\mathrm{FcRn}$ binding while the dimeric forms of $\mathrm{CH} 2$ and $\mathrm{CH} 3$ fragments did not.
MOLECULAR MODELING AND DOCKING STUDIES OF FCRn COMPLEXES WITH MONOMERIC Fc, CH2, AND CH3 DOMAINS

To understand the details of potential molecular interactions underlying FcRn binding with the $\mathrm{Fc}$ fragments $\mathrm{mFc}, \mathrm{mCH} 2$, and $\mathrm{mCH} 3$, homology-based molecular modeling of hFcRn and the Fc fragments was carried out. We then used these models for docking of $\mathrm{hFcRn}$ complexes with $\mathrm{mFc}, \mathrm{mCH} 2$, and $\mathrm{mCH} 3$ fragments to compare the possible difference between the complexes in $\mathrm{hFcRn}$ binding and properties. Figure 4 depicts the docked model of $\mathrm{hFcRn}-\mathrm{mFc} / \mathrm{Fc}$ complex as superimposed with the known rat FcRn-Fc complex structure. The structure of rat FcRn was used as a template for building the structure of its human counterpart.

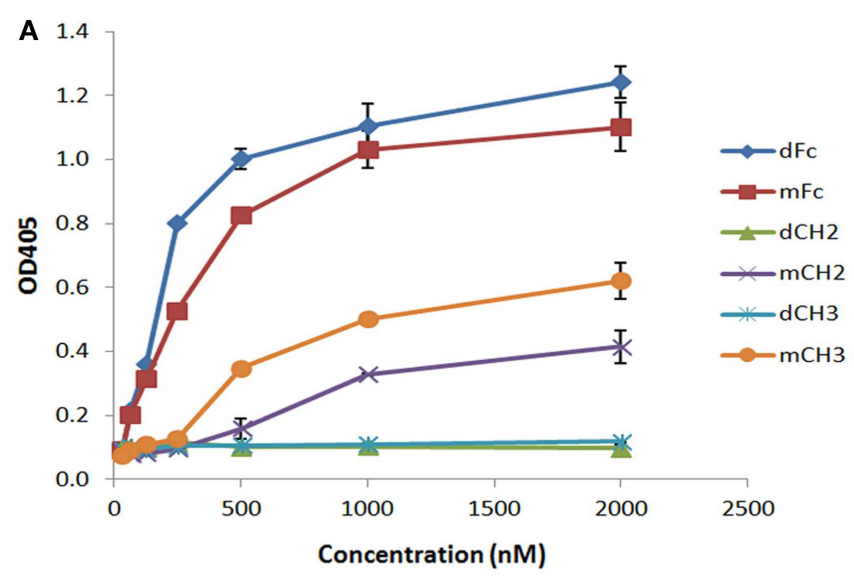

pH 6.0

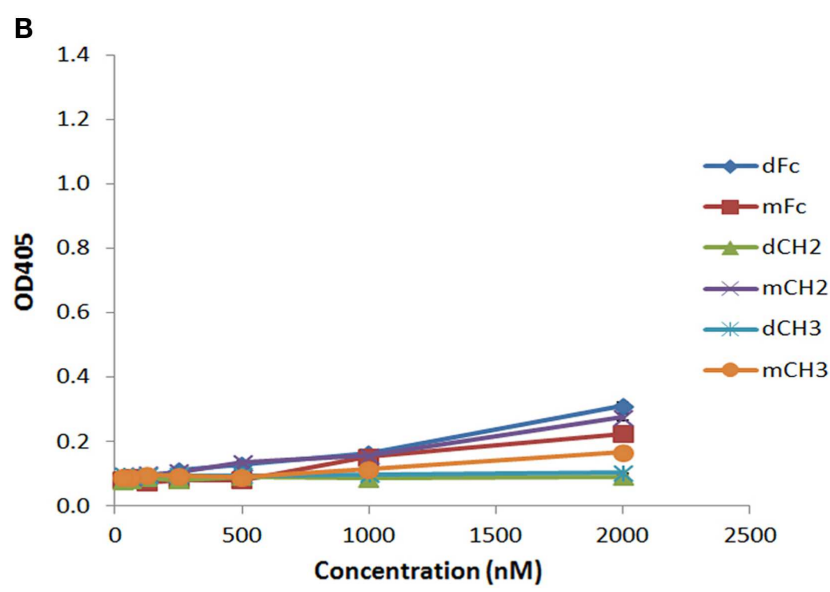

pH 7.4

FIGURE 3 | Binding of IgG1 Fc-dimeric/monomeric fragments, dFc/mFc, $\mathrm{mFc}, \mathrm{dCH} 2 / \mathrm{mCH} 2$, and $\mathrm{dCH} 3 / \mathrm{mCH} 3$, to $\mathrm{hFcRn}$ at $\mathrm{pH} 6.0$ (A) and pH 7.4 (B) measured by ELISA. The experimental points are represented as mean $\pm \mathrm{SD}(n=3)$.

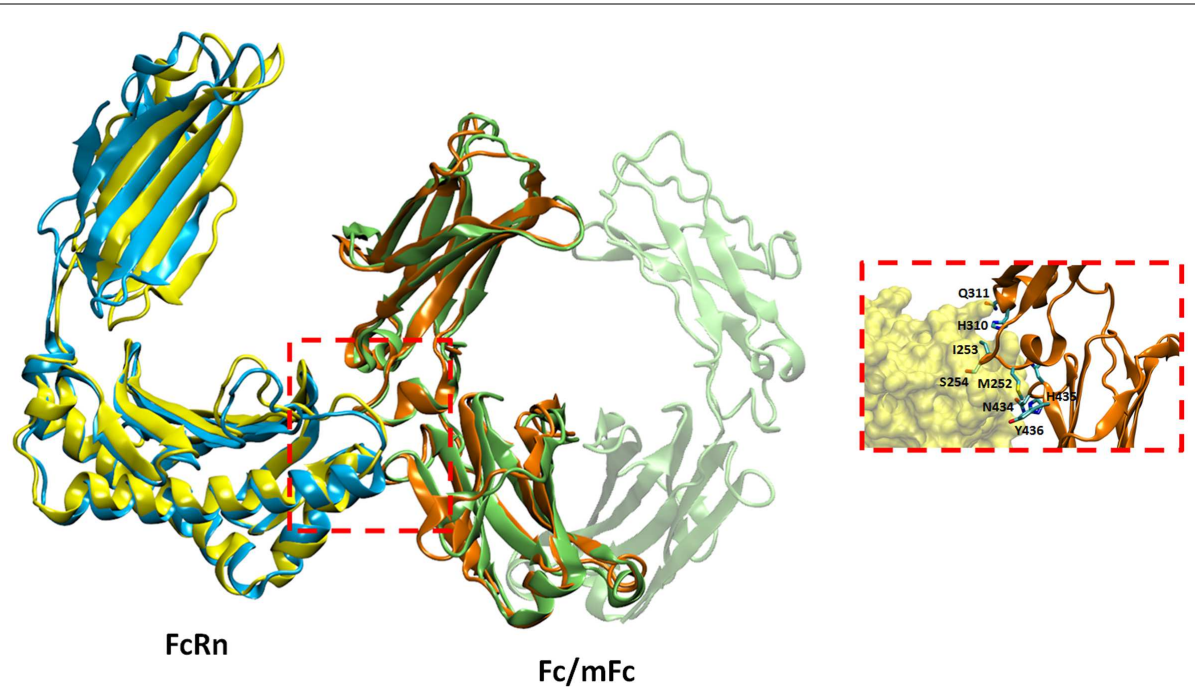

FIGURE 4 | Docked model of hFcRn-mFc complex as superimposed with the known rat FcRn-Fc complex structure. The inset shows a close-up view of the molecular interface of hFcRn (yellow surface) and $\mathrm{mFc}$ (orange ribbons) with potential binding residues (as sticks). 
Table 1 | Buried surface areas (BSA, $\AA^{2}$ ) and hydrogen bonds in human FcRn docked complexes with mFc, $\mathrm{CH} 2$, and $\mathrm{CH} 3$ fragments.

FcRn-mFc DOCKED COMPLEX

\begin{tabular}{|c|c|c|c|c|c|c|c|}
\hline FcRn & BSA (Å) & $\mathrm{mFc}$ & BSA (Å) & FcRn & & $\mathrm{mFc}$ & Distance $(\AA ̊)$ \\
\hline GLU 111 & 110.41 & ILE 253 & 136.06 & GLU 111[OE2] & $\ldots$ & HIS 310[N] & 2.85 \\
\hline PRO 128 & 98.42 & ARG 255 & 49.12 & ASP 126[O] & $\ldots$ & HIS 435[N] & 3.81 \\
\hline GLU 129 & 46.09 & LEU 309 & 27.19 & PRO 128[O] & $\ldots$ & TYR 436[OH] & 3.16 \\
\hline \multirow{3}{*}{ LEU 131} & & ASN 434 & 91.51 & & & & \\
\hline & & HIS 435 & 38.90 & & & & \\
\hline & & TYR 436 & 60.64 & & & & \\
\hline
\end{tabular}

FcRn-CH2 DOCKED COMPLEX

\begin{tabular}{lcccccc}
\hline FcRn & BSA (Å) & CH2 & BSA (Å) & FcRn & & CH2 \\
\hline TYR 84 & 15.30 & LEU 251 & 22.20 & GLU 112[N] & $\ldots$ & GLN 311[OE1] \\
LEU 108 & 28.13 & MET 252 & 38.86 & GLU 111[OE2] & $\ldots$ & HIS 310[ND1] \\
GLU 111 & 96.47 & ILE 253 & 122.93 & GLU 111[OE2] & $\ldots$ & HIS 310[N] \\
GLU 112 & 36.61 & SER 254 & 77.13 & GLU 129[OE1] & $\ldots$ & ILE 253[N] \\
TRP 127 & 130.11 & LEU 309 & 20.60 & GLU 129[OE2] & $\ldots$ & SER 254[N] \\
PRO 128 & 29.30 & HIS 310 & 31.51 & & 3.00 \\
GLU 129 & 43.40 & GLN 311 & 57.87 & & & 3.65 \\
& & LEU 314 & 23.87 & & &
\end{tabular}

FcRn-CH3 DOCKED COMPLEX

\begin{tabular}{|c|c|c|c|c|c|c|c|}
\hline FcRn & $\operatorname{BSA}(\AA)$ & $\mathrm{CH} 3$ & $\operatorname{BSA}(\AA)$ & FcRn & & $\mathrm{CH} 3$ & Distance $(\AA)$ \\
\hline ASP 126 & 91.07 & MET 428 & 25.31 & ASP 126[OD1] & $\ldots$ & HIS 433[ND1] & 2.91 \\
\hline TRP 127 & 27.44 & HIS 433 & 16.50 & ASP 126[OD1] & $\ldots$ & ASN 434[N] & 2.69 \\
\hline PRO 128 & 51.41 & ASN 434 & 65.11 & & & & \\
\hline LEU 131 & 67.82 & HIS 435 & 68.70 & & & & \\
\hline LEU 263 & 22.02 & TYR 436 & 53.79 & & & & \\
\hline
\end{tabular}

The root-mean-square deviation (RMSD) values for $\mathrm{C} \alpha$ atoms were calculated as $1.39 \AA$ between the aligned human and rat FcRn components of modeled and known template structures. The inset of Figure 4 shows a close-up view highlighting the molecular interface of the hFcRn (yellow surface) and $\mathrm{mFc}$ (orange ribbons) complex, along with the amino acid residues of $\mathrm{mFc}$ (in sticks) that could potentially make contact with the hFcRn. The FcRn-mFc interface accounts for a total of $1,261 \AA^{2}$ buried surface area and involves specific interactions such as hydrogen bonds, salt bridges, and hydrophobic interactions. These interactions occur mostly at the hinge region between $\mathrm{CH} 2$ and $\mathrm{CH} 3$ domains of $\mathrm{mFc}$, which contains several histidine and charged residues (Table 1) that resemble the rat FcRn/heterodimeric Fc complex (19).

The docked models of hFcRn complexes with $\mathrm{mCH} 2$ and $\mathrm{mCH} 3$ were illustrated in Figure 5. The overall contribution to the binding interface areas of these model complexes are much smaller, with 807 and $584 \AA^{2}$ of buried surface areas at the interface of $\mathrm{hFcRn}-\mathrm{mCH} 2$ and $\mathrm{hFcRn}-\mathrm{mCH} 3$, respectively, compared to the FcRn-mFc model complex. However, some of the critical intermolecular salt bridges were found between hFcRn and $\mathrm{Fc}$ fragment - $\mathrm{mFc}, \mathrm{mCH} 2$, and $\mathrm{mCH} 3$ - docking model complexes. In particular, His310 in $\mathrm{CH} 2$ and His433 in $\mathrm{CH} 3$ could interact with the acidic residues Glu112 and Asp126 of FcRn, respectively. Similar salt bridges between Fc histidine residues, His310 and His435, and FcRn acidic residues, Glu111/Asp126, respectively, were observed in the $\mathrm{hFcRn}-\mathrm{mFc}$ model complex. The putative titrating salt bridges that involve acidic-histidine residue pairs at the interfaces of hFcRn-mFc, hFcRn-mCH2, and hFcRn-mCH3 complexes might be ascribed to the mechanism of $\mathrm{pH}$-dependent FcRn binding. The different intermolecular interactions predicted in the docked model $\mathrm{hFcRn}$ complexes of $\mathrm{mFc}, \mathrm{mCH} 2$, and $\mathrm{mCH} 3$ fragments may have resulted in their differential binding properties (Figure 3).

One last consideration is that the preferential binding of $\mathrm{hFcRn}$ to $\mathrm{mCH} 2 / \mathrm{mCH} 3$ over their dimeric counterparts, $\mathrm{dCH} 2 / \mathrm{dCH} 3$, as 


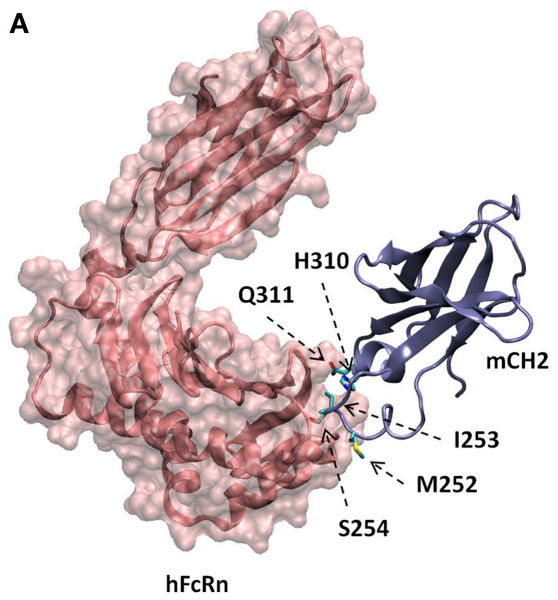

\section{B}

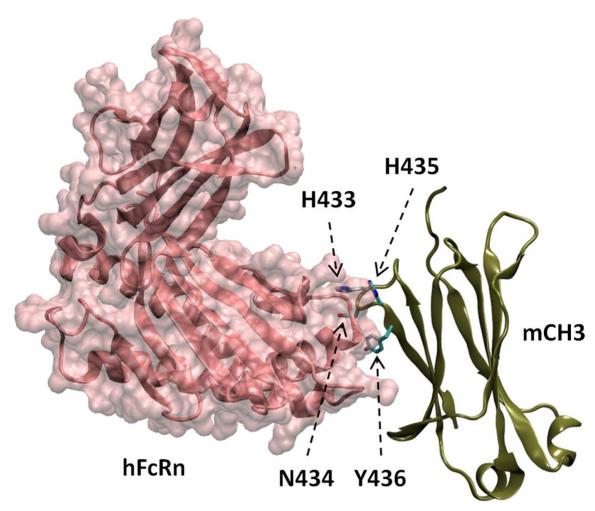

FIGURE 5 | Docked models of $\mathrm{hFcRn}$ complexes with $\mathrm{mCH} 2$ (A) and $\mathrm{mCH} 3(\mathrm{~B})$, showing with putative amino acids in $\mathrm{mCH} 2$ and $\mathrm{mCH} 3$ domains involved in the interactions with hFcRn.

seen in Figure 3, may be due to the exposure of additional residues after the monomerization of the dimers. It may not be due to the size-dependent effect alone since the $\mathrm{hFcRn}$ binding to $\mathrm{dFc}$ and $\mathrm{mFc}$ were much stronger. However, it should be noted that these data were obtained only using an ELISA assay where the protein conformation may not completely mimic the conformation in their native state as expressed at the cell surface. Further studies using natively expressed proteins are needed to validate these findings.

\section{CONCLUSION}

In summary, this study suggests that $\mathrm{mCH} 2$ and $\mathrm{mCH} 3$ could be potentially applicable in the engineering and development of novel biopharmaceuticals due to their high serum stability and $\mathrm{pH}$ dependent FcRn binding. We found that while both monomeric and dimeric $\mathrm{CH} 2$ and $\mathrm{CH} 3$ domains had high serum stability and exhibited varying aggregation tendencies, only $\mathrm{mCH} 2$ and $\mathrm{mCH} 3$ bound to FcRn at pH 6.0. None of the antibody fragments bound to $\mathrm{FcRn}$ at $\mathrm{pH}$ 7.4. Our molecular modeling and docking studies suggest that this preferential binding of $\mathrm{mCH} 2$ and $\mathrm{mCH} 3$ to $\mathrm{FcRn}$ may be due to additional exposed residues from their monomerization. The smaller size and other described properties of $\mathrm{mCH} 2$ and $\mathrm{mCH} 3$ would overcome the fundamental problem of full-size antibodies, resulting in enhanced tissue penetration and providing access to a wide range of targets that are sterically occluded.

\section{ACKNOWLEDGMENTS}

We thank Dr. Sergey G. Tarasov and Marzena A. Dyba of the Biophysics Resource in the Structural Biophysics Laboratory, NCIFrederick for helpful discussions and technical support. This research was supported by the Intramural Research Program of the $\mathrm{NIH}$, National Cancer Institute, Center for Cancer Research, and by Federal funds from the NIH, National Cancer Institute, under contract numbers NO1-CO-12400 and HHSN261200800001E. The content of this publication does not necessarily reflect the views or policies of the Department of Health and Human Services, nor does the mention of trade names, commercial products, or organizations imply endorsement by the U.S. Government.

\section{REFERENCES}

1. Dimitrov DS. Therapeutic proteins. Methods Mol Biol (2012) 899:1-26. doi:10. 1007/978-1-61779-921-1_1

2. Carter PJ. Potent antibody therapeutics by design. Nat Rev Immunol (2006) 6(5):343-57. doi:10.1038/nri1837

3. Saerens D, Ghassabeh GH, Muyldermans S. Single-domain antibodies as building blocks for novel therapeutics. Curr Opin Pharmacol (2008) 8(5):600-8. doi:10.1016/j.coph.2008.07.006

4. Chen W, Gong R, Ying T, Prabakaran P, Zhu Z, Feng Y, et al. Discovery of novel candidate therapeutics and diagnostics based on engineered human antibody domains. Curr Drug Discov Technol (2014) 11(1):28-40.

5. Strohl WR, Strohl LM. Antibody fragments as therapeutics. Therapeutic Antibody Engineering: Current and Future Advances Driving the Strongest Growth Area in the Pharmaceutical Industry. Cambridge: Woodhead Publishing Series in Biomedicine (2013) p. 265-99.

6. Roopenian DC, Akilesh S. FcRn: the neonatal Fc receptor comes of age. Nat Rev Immunol (2007) 7(9):715-25. doi:10.1038/nri2155

7. Ghetie V, Ward ES. Multiple roles for the major histocompatibility complex class I-related receptor FcRn. Annu Rev Immunol (2000) 18:739-66. doi:10.1146/annurev.immunol.18.1.739

8. Kuo TT, Aveson VG. Neonatal Fc receptor and IgG-based therapeutics. MAbs (2011) 3(5):422-30. doi:10.4161/mabs.3.5.16983

9. Moreland LW, Baumgartner SW, Schiff MH, Tindall EA, Fleischmann RM, Weaver AL, et al. Treatment of rheumatoid arthritis with a recombinant human tumor necrosis factor receptor (p75)-Fc fusion protein. N Engl J Med (1997) 337(3):141-7. doi:10.1056/NEJM199707173370301

10. Gehlsen K, Gong R, Bramhill D, Wiersma D, Kirkpatrick S, Wang Y, et al. Pharmacokinetics of engineered human monomeric and dimeric $\mathrm{CH} 2$ domains. MAbs (2012) 4(4):466-74. doi:10.4161/mabs.20652

11. Ying T, Chen W, Feng Y, Wang Y, Gong R, Dimitrov DS. Engineered soluble monomeric IgG1 CH3 domain: generation, mechanisms of function, and implications for design of biological therapeutics. J Biol Chem (2013) 288(35):25154-64. doi:10.1074/jbc.M113.484154

12. Ying T, Chen W, Gong R, Feng Y, Dimitrov DS. Soluble monomeric IgG1 Fc. J Biol Chem (2012) 287(23):19399-408. doi:10.1074/jbc.M112.368647

13. Gong R, Wang Y, Feng Y, Zhao Q, Dimitrov DS. Shortened engineered human antibody $\mathrm{CH} 2$ domains: increased stability and binding to the human neonatal Fc receptor. J Biol Chem (2011) 286(31):27288-93. doi:10.1074/jbc.M111. 254219

14. Gong R, Wang Y, Ying T, Dimitrov DS. Bispecific engineered antibody domains (nanoantibodies) that interact noncompetitively with an HIV-1 neutralizing 
epitope and FcRn. PLoS One (2012) 7(8):e42288. doi:10.1371/journal.pone. 0042288

15. Wozniak-Knopp G, Bartl S, Bauer A, Mostageer M, Woisetschlager M, Antes B, et al. Introducing antigen-binding sites in structural loops of immunoglobulin constant domains: Fc fragments with engineered HER2/neu-binding sites and antibody properties. Protein Eng Des Sel (2010) 23(4):289-97. doi:10.1093/ protein/gzq005

16. Gong R, Vu BK, Feng Y, Prieto DA, Dyba MA, Walsh JD, et al. Engineered human antibody constant domains with increased stability. J Biol Chem (2009) 284(21):14203-10. doi:10.1074/jbc.M900769200

17. Gong R, Chen W, Dimitrov DS. Expression, purification, and characterization of engineered antibody $\mathrm{CH} 2$ and VH domains. Methods Mol Biol (2012) 899:85-102. doi:10.1007/978-1-61779-921-1_6

18. Feng Y, Gong R, Dimitrov DS. Design, expression and characterization of a soluble single-chain functional human neonatal Fc receptor. Protein Expr Purif (2011) 79(1):66-71. doi:10.1016/j.pep.2011.03.012

19. Martin WL, West AP Jr, Gan L, Bjorkman PJ. Crystal structure at 2.8 A of an FcRn/heterodimeric Fc complex: mechanism of pH-dependent binding. $\mathrm{Mol}$ Cell (2001) 7(4):867-77. doi:10.1016/S1097-2765(01)00230-1

20. Bordoli L, Kiefer F, Arnold K, Benkert P, Battey J, Schwede T. Protein structure homology modeling using SWISS-MODEL workspace. Nat Protoc (2009) 4(1):1-13. doi:10.1038/nprot.2008.197

21. Phillips JC, Braun R, Wang W, Gumbart J, Tajkhorshid E, Villa E, et al. Scalable molecular dynamics with NAMD. J Comput Chem (2005) 26(16):1781-802. doi:10.1002/jcc.20289
22. Chen R, Li L, Weng Z. ZDOCK: an initial-stage protein-docking algorithm. Proteins (2003) 52(1):80-7. doi:10.1002/prot.10389

23. Humphrey W, Dalke A, Schulten K. VMD: visual molecular dynamics. J Mol Graph (1996) 14(1):33-8. doi:10.1016/0263-7855(96)00018-5

24. Krissinel E, Henrick K. Inference of macromolecular assemblies from crystalline state. J Mol Biol (2007) 372(3):774-97. doi:10.1016/j.jmb.2007.05.022

Conflict of Interest Statement: The authors declare that the research was conducted in the absence of any commercial or financial relationships that could be construed as a potential conflict of interest.

Received: 22 January 2014; paper pending published: 19 February 2014; accepted: 20 March 2014; published online: 02 April 2014.

Citation: Ying T, Ju TW, Wang Y, Prabakaran P and Dimitrov DS (2014) Interactions of IgG1 CH2 and CH3 domains with FcRn. Front. Immunol. 5:146. doi: 10.3389/fimmu.2014.00146

This article was submitted to Immunotherapies and Vaccines, a section of the journal Frontiers in Immunology.

Copyright (c) 2014 Ying, Ju, Wang, Prabakaran and Dimitrov. This is an open-access article distributed under the terms of the Creative Commons Attribution License (CC $B Y)$. The use, distribution or reproduction in other forums is permitted, provided the original author(s) or licensor are credited and that the original publication in this journal is cited, in accordance with accepted academic practice. No use, distribution or reproduction is permitted which does not comply with these terms. 